\title{
Impedance Analysis on Transient Behavior of DMFC Anodes during Preconditioning Process
}

\author{
Joon-Hee Kim, ${ }^{\text {a,c }}$ Ho-In Lee, ${ }^{\text {a }}$ Seong-Ahn Hong, ${ }^{\text {b }}$ and Heung Yong $\mathrm{Ha}^{\mathrm{b}, *, \mathrm{z}}$ \\ ${ }^{a}$ School of Chemical Engineering and Research Center for Energy Conversion and Storage, Seoul National \\ University, Seoul 151-744, Korea \\ ${ }^{b}$ Fuel Cell Research Center, Korea Institute of Science and Technology, Seoul 136-791, Korea
}

Transient behavior of direct methanol fuel cells (DMFCs) during the preconditioning process has been investigated with a focus on changes manifested in the anode by using an electrochemical impedance spectroscopic analysis. Preconditioning of membrane electrode assembly (MEA) is essential to achieve maximum cell performance, and the time required to accomplish the conditioning may vary depending on the methods that are adopted. Preconditioning temperature substantially influences the behaviors of MEAs, and room-temperature treatment has been found to be more favorable than high-temperature treatment at $90^{\circ} \mathrm{C}$. Application of electric load during the preconditioning process accelerates the hydration of electrolyte and thus reduces the time required to reach a maximum performance limit. The anode impedance data of DMFC has been deconvoluted by using an equivalent circuit to investigate three kinds of resistances in the MEA, such as resistance of charge transfer $\left(R_{\mathrm{ct}}\right)$, electrolytes $\left(R_{e}\right)$, and pore electrolytes $\left(R_{p}\right)$. The underpinning mechanism which causes the change in performance during the preconditioning process is discussed in terms of the changes in the resistance elements of the anode.

(C) 2005 The Electrochemical Society. [DOI: 10.1149/1.2109468] All rights reserved.

Manuscript submitted November 11, 2004; revised manuscript received August 3, 2005. Available electronically October 24, 2005.

In recent times, intense research interest has been channeled in improving the performance of direct methanol fuel cells (DMFCs) based on polymer electrolyte membranes. Performance of a DMFC is strongly influenced not only by the fabrication procedure of membrane electrode assembly (MEA) but also by the preconditioning method adopted. Hence, to improve the performance of DMFCs, it is important to establish an appropriate conditioning method for MEAs. Several methods have been proposed for conditioning of MEAs to achieve a stable and improved performance of DMFCs. ${ }^{1-4}$ In DMFCs as in the case of polymer electrolyte membrane fuel cell (PEMFCs), sufficient hydration of polymer electrolyte membrane and recast ionomer in the catalyst layer is necessary to obtain stable proton conductivity, and hence the hydration process might require about 24-48 h. For instance, Aricó et al. ${ }^{1}$ supplied water to both the anode and cathode compartments of a DMFC, and the cell was warmed up stepwise to a maximum operating temperature of $95^{\circ} \mathrm{C}$, followed by an operation with the supply of methanol $(0.5 \mathrm{M})$ and oxygen at a high current for a period of $24 \mathrm{~h}$. Shukla et al. ${ }^{2}$ collected the polarization curves of DMFCs after hydrating the MEAs for $24 \mathrm{~h}$ by circulating a $2 \mathrm{M}$ methanol solution through the anode compartment at $80^{\circ} \mathrm{C}$. Scott et al. ${ }^{3}$ adopted both the above methods. They ${ }^{4}$ suggested that hydrogen evolution on electrodes could influence the performance of DMFCs by reducing the overpotential of both oxygen reduction as well as methanol oxidation reactions. Though various routes have been employed for conditioning MEAs, to the best of our knowledge, no definite explanation has been offered in the literature on the mechanism of performance changes that occur during the conditioning period, except a brief mention in our previous study. ${ }^{5}$

Our present investigation has set out to study the transient behaviors of DMFCs during the preconditioning process of MEAs by using an impedance analysis technique. To evaluate the measured anode impedance data, an appropriate equivalent circuit has been proposed which contains impedance elements representing the electrode structure and the various reaction steps involved in a methanol oxidation reaction. The mechanism of performance change by the preconditioning process is discussed in terms of resistance elements.

\footnotetext{
* Electrochemical Society Active Member.

${ }^{c}$ Present address: Fuel Cell Program Team, Samsung Advanced Institute of Technology, Gyeonggi-do, Korea 449-721.

z E-mail: hyha@kist.re.kr
}

\section{Impedance Elements in an Equivalent Circuit}

Basic elements. - The impedance of a solid electrode having a smooth surface may be described by a simple model consisting of two impedance elements: ${ }^{6}$ charge-transfer resistance $\left(R_{p}\right)$ and double-layer capacitance $\left(C_{d}\right)$. A resistor may be appended to represent an electrolyte resistance $\left(R_{e}\right)$. In order to describe a porous anode and a methanol electro-oxidation in the DMFC, a few additional steps are required. For this purpose, an equivalent circuit has been constructed and equations were formulated in order to calculate the different resistances which exist in the anode. The equivalent circuit depicted in Fig. 1 is explained elsewhere, ${ }^{5}$ but we briefly present the same below to facilitate the readers' understanding.

Porous layer.- Porous electrodes in PEMFCs may be described using various models. ${ }^{7,8}$ In general, a correlation exists between the geometry of the model and the simplicity of the impedance elements used. Thus, the model used here is based on a relatively simple geometry, assuming a system of homogeneous pores as suggested by Göhr. ${ }^{9}$ The impedance of the porous layer may be expressed in terms of macroscopic impedance elements such as $Z_{p}$, the impedance of the pores filled with electrolyte, $Z_{m}$, the impedance of the porous metal catalyst, and $Z_{q}$, the impedance of the interface (porous layer|pore).

The impedance $Z_{p}$ and $Z_{m}$ can be reduced to resistive elements, $R_{p}$ and $R_{m}$. In this study, the term $R_{m}$ can be neglected assuming a value of zero. The expression for the total impedance $\left(R_{\mathrm{pl}}\right)$ in the porous layer may appear complex but can be calculated by using the approach of Göhr, ${ }^{9}$ as given in Eq. 1

$$
Z_{\mathrm{pl}}=\frac{\sqrt{R_{p} Z_{q}}}{\tanh \left(\sqrt{R_{p} / Z_{q}}\right)}
$$

Relaxation impedance.- According to Schiller et al., ${ }^{10}$ the impedance spectra of the Pt anode in a PEMFC show a strong time dependence and exhibit a pseudo-inductive contribution in the lowfrequency region of the spectra due to the influence of carbon monoxide poisoning. The pseudo-inductive behavior can be attributed to the surface relaxation process of the anode. It is already known that the oxidation of adsorbed carbon monoxide in the mechanism of methanol oxidation is a rate-determining step. ${ }^{11}$ Thus, the same phenomena may be found in the DMFC anode, and a relaxation impedance term $\left(Z_{k}\right)$ should be included.

The relaxation impedance may be included in a model of faradaic impedance $\left(Z_{F}\right)$ at nonequilibrium potential. ${ }^{10}$ The faradaic impedance, which describes either the mass transport or the reaction 


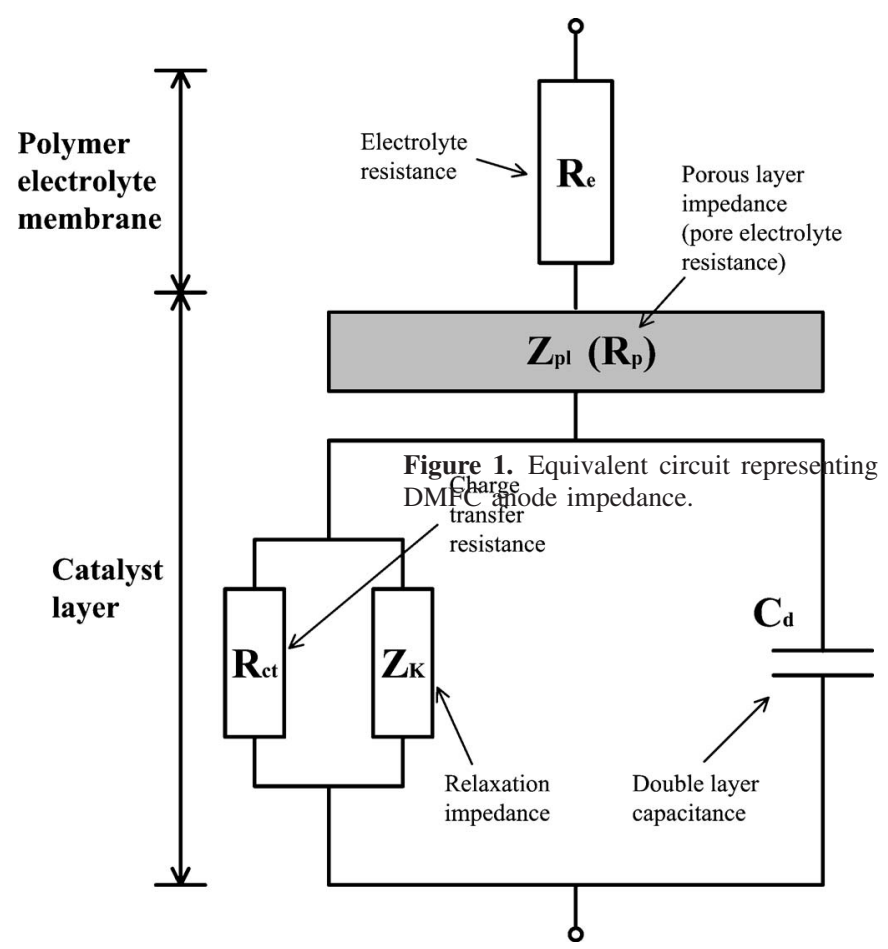

mechanism at the electrode, ${ }^{12}$ is composed of a potential-dependent charge-transfer resistance $\left(R_{c t}\right)$ and a time-dependent relaxation impedance, as given in Eq. 2

$$
Z_{F}=\frac{R_{\mathrm{ct}} Z_{K}}{R_{\mathrm{ct}}+Z_{K}}
$$

Therefore, total impedance $(Z)$ and an equivalent circuit of DMFC anode in this study have been proposed, as given in Eq. 3 and shown in Fig. 1

$$
Z=R_{e}+Z_{\mathrm{pl}}+\frac{1}{1 / Z_{F}+j \omega C_{d}}
$$

\section{Experimental}

Preparation of MEAs. - The cathode catalyst used for oxygen electroreduction was $47 \mathrm{wt} \% \mathrm{Pt} / \mathrm{C}$ (Tanaka), and the anode catalyst used for methanol electro-oxidation was 53 wt \% PtRu/C (Tanaka). Catalyst ink was prepared by mixing appropriate amounts of catalyst in deionized water, a 5\% Nafion solution (1100 EW, DuPont), and isopropyl alcohol (IPA) for the cathode and dipropyl ketone (DPK) for the anode. The electrodes were obtained by spraying the catalyst ink onto a $10 \mathrm{~cm}^{2}$ of carbon paper (TGPH-060, Toray). The metal (Pt or PtRu) loading was $3 \mathrm{mg} / \mathrm{cm}^{2}$ in each electrode, and the total ionomer loading was $30 \mathrm{wt} \%$ to catalyst (ratio of dry ionomer to catalyst multiplied by 100) for the cathode and $60 \mathrm{wt} \%$ to catalyst for the anode. A pair of electrodes (cathode and anode) was hotpressed on both sides of the polymer electrolyte membrane (Nafion 117 , DuPont) at a temperature of $140^{\circ} \mathrm{C}$ and with a pressure of $7 \mathrm{MPa}$ for $150 \mathrm{~s}$.

Single-cell testing.- All experiments including electrochemical measurements were conducted with cells which consisted of MEAs sandwiched between two graphite plates with a serpentine flow field. In all experiments operated in a fuel cell mode, $2 \mathrm{M}$ methanol solution was pumped through the anode side at a flow rate of $5 \mathrm{~mL} / \mathrm{min}$ and oxygen to the cathode side at a flow rate of $250 \mathrm{sccm}$. Single-cell measurements were made at $90^{\circ} \mathrm{C}$ in atmospheric pressure. Oxygen gas was humidified by passing through a

\begin{tabular}{|c|c|c|c|c|}
\hline & MEA1 & MEA2 & MEA3 & MEA4 \\
\hline Temperature $\left({ }^{\circ} \mathrm{C}\right)$ & 25 & 90 & 25 & 90 \\
\hline Current $\left(100 \mathrm{~mA} / \mathrm{cm}^{2}\right)$ & $x$ & $x$ & 0 & 0 \\
\hline
\end{tabular}
humidifier maintained at a temperature of $65^{\circ} \mathrm{C}$. Current-voltage curves were measured galvanostatically by using an electric load (EL-500P, Daegil Electronics), and it took about $30 \mathrm{~min}$ to collect each polarization curve.

Preconditioning of MEAs.- In this investigation during the conditioning period of MEAs, the variables of our interest such as temperature $\left(25\right.$ or $\left.90^{\circ} \mathrm{C}\right)$ and electric load $\left(0\right.$ or $\left.100 \mathrm{~mA} / \mathrm{cm}^{2}\right)$ were chosen to study their effects on the performance of the DMFC (Table I). During the measurements of single-cell performance at $90^{\circ} \mathrm{C}$ while preconditioning MEAs, the time interval between adjacent measurements was either 6 or $12 \mathrm{~h}$. After measuring the cell performance, impedance analysis was made subsequently, and then the cell was maintained in the corresponding conditioning state (Table I) until the next measurement. For example, in the case of experiments with MEA3, the cell was first maintained at $25^{\circ} \mathrm{C}$ at a load of $100 \mathrm{~mA} / \mathrm{cm}^{2}$ while feeding methanol solution to the anode and oxygen to the cathode for $6 \mathrm{~h}$, and then its temperature was raised to $90^{\circ} \mathrm{C}$ to measure an $\mathrm{i}-\mathrm{V}$ pattern followed by impedance tracings. Then the temperature was lowered to $25^{\circ} \mathrm{C}$ again while the load was maintained at $100 \mathrm{~mA} / \mathrm{cm}^{2}$ until the next cycle.

Characterization of MEAs. - The impedance spectra were obtained on the operating cells with a potentiostat (IM6, Zahner). The anode was supplied with a $2 \mathrm{M}$ methanol solution $(5 \mathrm{~mL} / \mathrm{min})$ at $90^{\circ} \mathrm{C}$ and the cathode with a continuous stream of dry hydrogen $(200 \mathrm{sccm})$ to make a dynamic hydrogen electrode (DHE) and to facilitate the removal of permeated water. All anode impedance spectra reported here were measured between the anode and DHE in the complete fuel cell. The frequency was varied from $50 \mathrm{mHz}$ to $1 \mathrm{kHz}$, and the amplitude of sinusoidal current signal was adjusted so that the potential amplitude did not exceed $5 \mathrm{mV}$. Every spectrum was measured at a de potential of $0.4 \mathrm{~V}$ (vs DHE).

The porous microstructure of the anode was investigated by using a scanning electron microscope (SEM) of type S-4200 (Hitachi).

\section{Results and Discussion}

When a freshly made MEA is assembled in a cell fixture, it is usually in a dry state, and thus it takes some time to reach full performance under standard operating conditions. In this study, we have varied the temperature and the extent of the electric load applied to the cell during the preconditioning process, as listed in Table I. Figure 2 shows the changes in the single-cell performances of different MEAs with time on stream. In the cases of MEA1 and MEA2, the reactants were supplied continuously during the conditioning process at 25 and $90^{\circ} \mathrm{C}$, respectively. In cases of MEA3 and MEA4, a constant load $\left(100 \mathrm{~mA} / \mathrm{cm}^{2}\right)$ was applied under the condition of MEA1 and MEA2, respectively. It can be seen from the performance pattern of MEA1 that the performance increases steeply during the first $12 \mathrm{~h}$ to reach a maximum value. The other MEAs also exhibit similar tendencies, though the extent of variation depends on the conditioning methods. Figure 3 shows the changes in the current densities of all four types of MEAs shown in Fig. 2 as a function of conditioning time at a cell voltage of $0.4 \mathrm{~V}$. The rates of changes in performance and the time required to obtain a maximum value vary from one another. It is reasonable to assume that these differences might be caused by the temperature and the electrochemical reactions which take place at the MEAs during the conditioning process. The MEAs treated at $25^{\circ} \mathrm{C}$ (RT-treated MEAs: MEA1 and MEA3) exhibited better performance than those treated at $90^{\circ} \mathrm{C}$ (HT-treated MEAs: MEA2 and MEA4). The MEAs (MEA3 


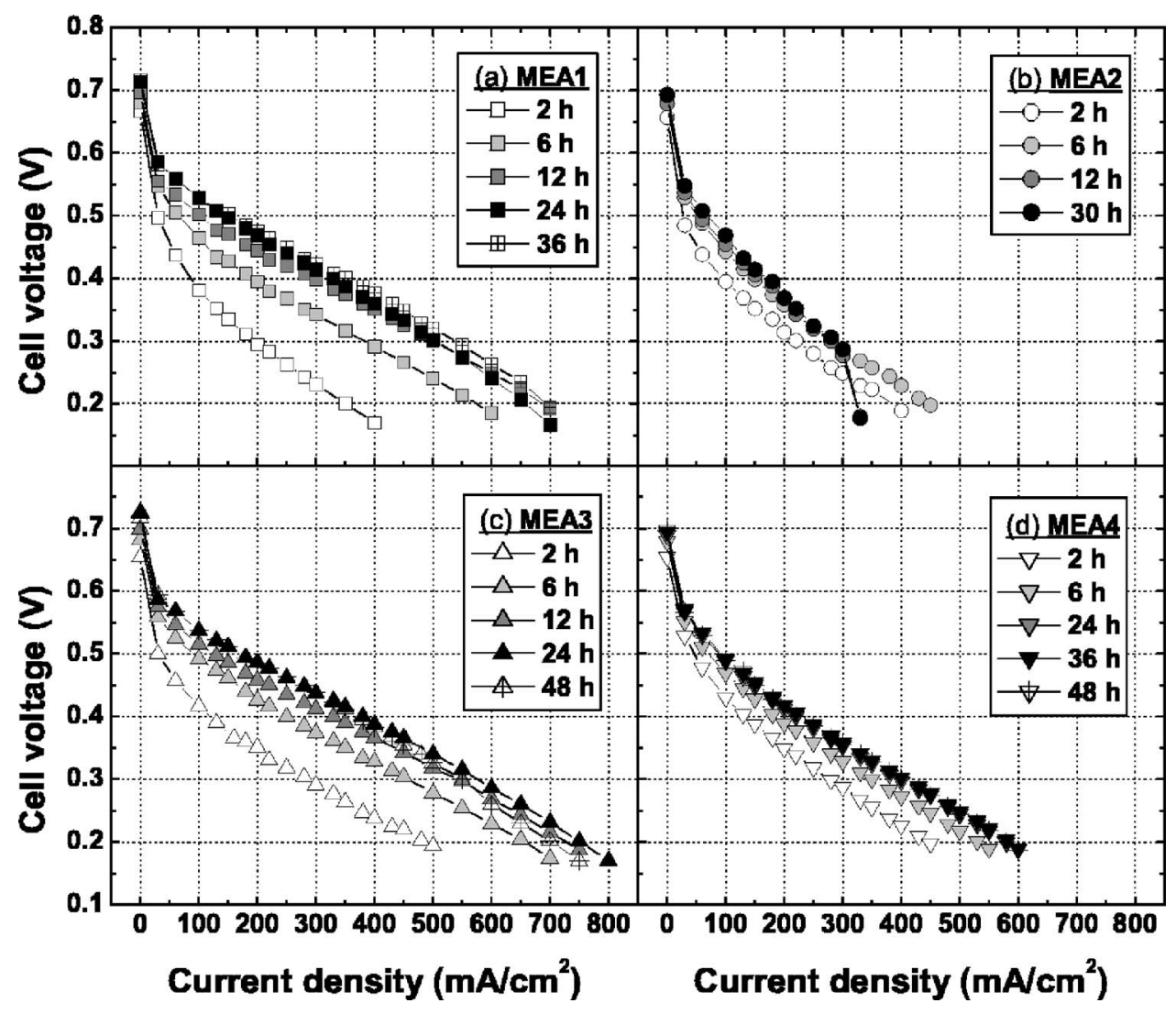

Figure 2. Performances of MEAs during various preconditioning processes: (a) treated at $25^{\circ} \mathrm{C}$ and open-circuit voltage $(\mathrm{OCV}),(\mathrm{b})$ treated at $90^{\circ} \mathrm{C}$ and $\mathrm{OCV},(\mathrm{c})$ treated at $25^{\circ} \mathrm{C}$ and $100 \mathrm{~mA} / \mathrm{cm}^{2}$, and (d) treated at $90^{\circ} \mathrm{C}$ and $100 \mathrm{~mA} / \mathrm{cm}^{2}$. and MEA4) that were treated with an application of a constant load $\left(100 \mathrm{~mA} / \mathrm{cm}^{2}\right)$ exhibited better performance than those (MEA1 and MEA2) treated in an open-circuit state.

From these results, one can clearly see that the preconditioning process has a significant effect on the performance of the DMFC, depending on the steps adopted during the process. Particularly the temperature appears as a main factor that determines the performance of the MEA. Siroma et al. ${ }^{13}$ observed that the recast film of Nafion ionomer was dissolved in an aqueous methanol solution at $80^{\circ} \mathrm{C}$, even if the film was treated with a hot-pressing process. Hence, there is a possibility that the recast ionomer in the anode catalyst layer could be dissolved or at least the polymer structure could have been considerably loosened when the MEA is in contact

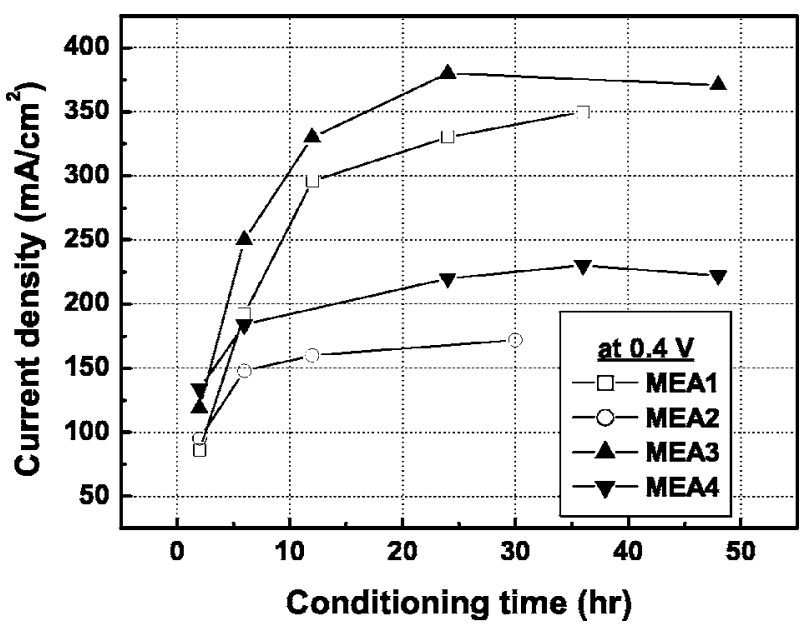

Figure 3. Performances of MEAs at $0.4 \mathrm{~V}$ as a function of conditioning time. Rearrangement of the data in Fig. 2. with a methanol solution. The structural changes in the recast ionomer can be further affected by the concentration and temperature of methanol solution.

The mechanism involved in the performance change in MEA during the preconditioning process may be explained as follows. When the MEA is in contact with a methanol solution at room temperature, the recast ionomer in the catalyst layer is hydrated and undergoes considerable swelling. Therefore, the interfacial area between the ionomer and catalyst particles may widen, causing an enhancement in the three-phase boundary that is required for electrochemical reaction, and the ionomer network in the catalyst layer may also build up significantly to increase the ionic conductance, leading to an improvement in the activity of the MEA. However, when the MEA is supplied with a methanol solution at high temperature (90C), the recast ionomer may experience excessive swelling as well as dissolution in the solution, which may reduce both the ionic conductance and the area of the three-phase boundary. Due to these two reasons, there is no appreciable improvement in the cell performance with the MEAs that were preconditioned at high temperature, in spite of a faster hydration rate.

In the case of the MEAs to which constant loads were applied during the conditioning process (MEA3 and MEA4), the electrolyte membrane and catalyst might have been affected due to following reasons. The processing of an electrochemical reaction under the electric load could accelerate the hydration rate and thus quickly stabilize the proton conductivity of the membrane by the water transported from the anode to the cathode driven by electro-osmotic drag. ${ }^{13}$ Moreover, the electrochemical reaction on the electrodes could have activated the catalyst by increasing the roughness of catalyst surface ${ }^{14,15}$ and consequently improve the activity of the electrodes. In our previous investigation, ${ }^{5}$ it was observed that the resistances in electrolyte membrane and proton-conducting ionomer in the catalyst layer decreased during the conditioning period, and the secondary pore size increased due to structural change of the catalyst layer caused by ionomer swelling. These changes are pre- 


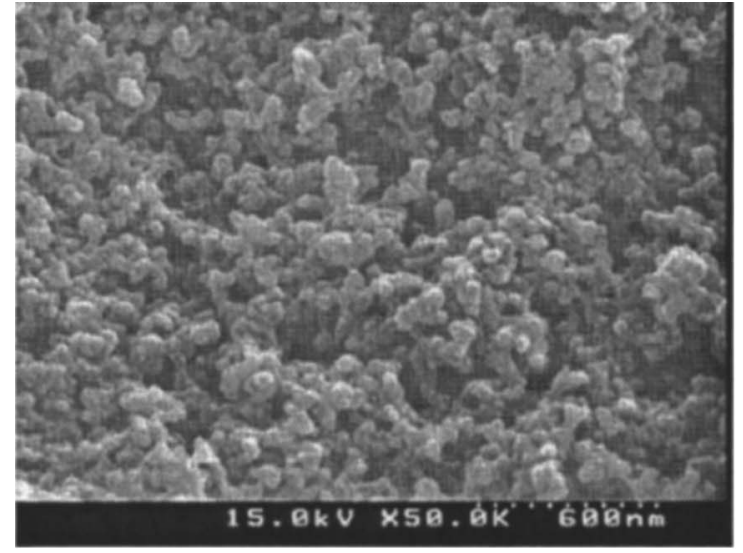

(a)

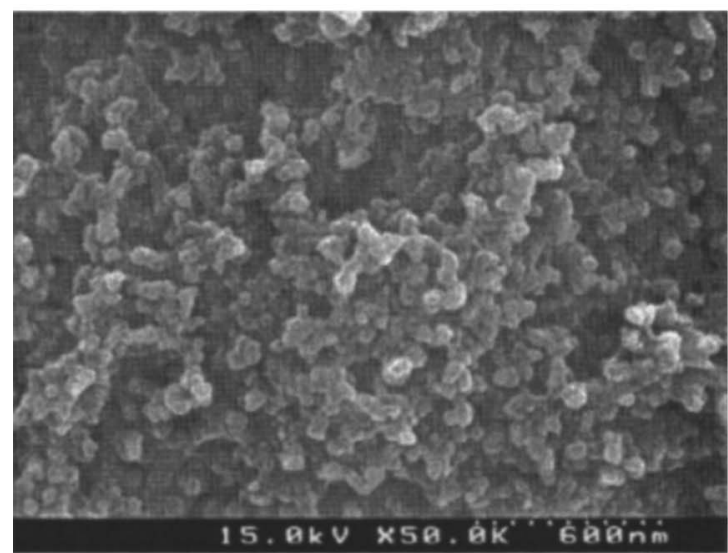

(c)

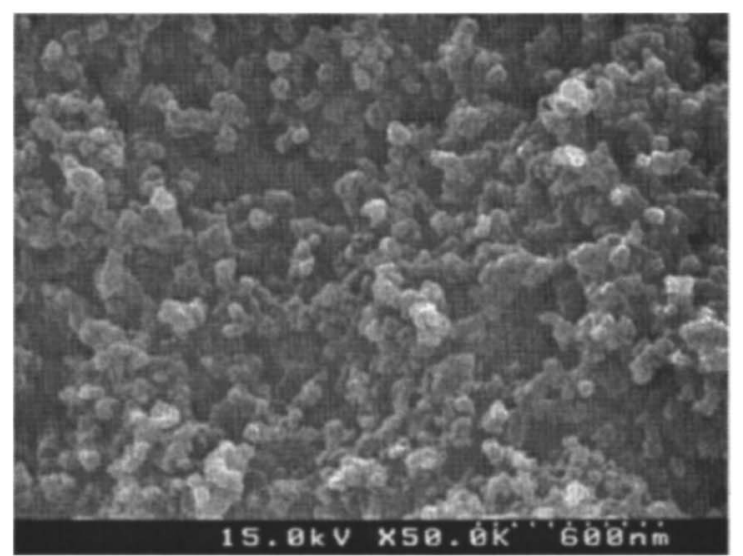

(e)

sumed to be the primary factors responsible for improving the performance of MEAs during the conditioning period.

Single-cell performance is directly influenced by both the mass and charge-transfer processes. The mass-transfer process is facilitated in the large secondary pores $(0.04-1.0 \mu \mathrm{m})$, which originate from the space among agglomerates of catalyst particles and ionomer. ${ }^{16}$ However, in this study, mass-transfer limitation in the high-current-density region was not apparent in the I-V curve (Fig. 2) because a reasonably high concentration of methanol (2 M) was used. Actually, it was hard to find any prominent structural changes in the SEM images (Fig. 4) of each of the MEAs before and after the
Figure 4. SEM images of anodes before and after conditioning period: (a) as-prepared, (b) MEA1, (c) MEA2, (d) MEA3, and (e) MEA4.

conditioning process, though there must be certain microscopic structural changes in the catalyst layer of the electrode. ${ }^{5}$

Various resistances associated with the methanol oxidation process at the DMFC anode can be measured using an impedance analysis technique. The impedance data of the anode with each MEA during the conditioning period is shown in Fig. 5. The experimental data, along with numerical data calculated using the equivalent circuit (Fig. 1), has been illustrated. In the anode impedance spectra of MEA1, the electrolyte resistance $\left(Z_{R e}=R_{e}\right.$ at the point of $Z_{I m}=0$ in the high-frequency range, the smaller intercept on the real part of the axis) and charge-transfer resistance $\left(R_{\mathrm{ct}}\right.$, diameter of the 


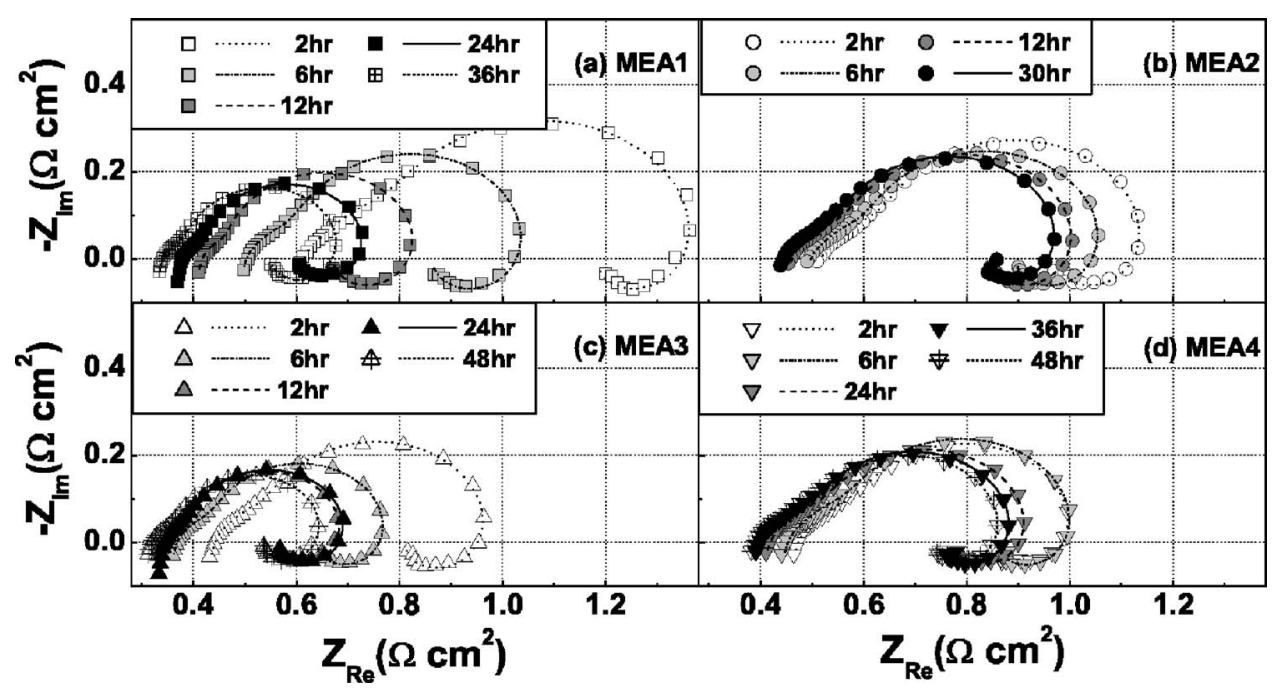

Figure 5. Impedance data of anodes during various preconditioning processes. Symbols: experimental data, lines: numerical data. semicircle) decreased gradually over the first $12 \mathrm{~h}$, while the singlecell performance increased. These results indicate that the resistances decrease gradually primarily due to the hydration of the polymer electrolyte in the MEA during the conditioning. The other MEAs also experienced a fall in resistances in a similar fashion, though the extents of variation depended on the conditioning methods. $R_{e}$ and $R_{\mathrm{ct}}$ of the HT-treated MEAs in the right column (MEA2 and MEA4) show gradual decreasing rates but still have higher values compared to the RT-treated MEAs in the left column (MEA1 and MEA3). This might be attributed to the increased contact resistance either between the electrode and the electrolyte membrane or between the recast ionomer and catalyst particles in the catalyst layer. When the single-cell fixture was dismantled after the completion of single-cell tests, it was noticed that the electrodes of HTtreated MEAs were completely delaminated from the electrolyte membrane. The RT-treated MEAs were in undisturbed form, just like a fresh MEA. It can be inferred that the coherence between electrodes and electrolyte membrane is significantly decreased at high temperature due to excessive ionomer swelling and the loosened ionomer structure. ${ }^{17}$ The changes in the ionomer morphology influence the structure of the catalyst layer and the electrode delamination would significantly reduce the proton conductance, deteriorating the MEA performance.

The influence of structural changes in the catalyst layer on the electrochemical property of the anode was investigated using an impedance technique. The impedance data were fitted numerically with an equivalent circuit, as previously described in the theoretical section (Fig. 1). The numerical results matched well with the experimentally measured impedance data (Fig. 5), and thus it was possible to calculate several resistance elements from the anode impedance data, i.e., the resistances $R_{\mathrm{ct}}, R_{e}, R_{p}$, and a capacitance $C_{d} . R_{\mathrm{ct}}$ is a resistance that is involved in the methanol electro-oxidation process occurring at the interface of catalyst and ionomer in a catalyst layer. Therefore, $R_{\mathrm{ct}}$ is not only related to the effective area of three-phase region ${ }^{18}$ but also reflects the mass-transfer resistance. ${ }^{19}$ In general models, $R_{e}$ includes the resistances of the electrolyte membrane and pore electrolyte (i.e., recast ionomer) in the catalyst layer, but in this study the pore electrolyte resistance $R_{p}$ is extracted from $R_{e}$. The resistance associated with electron transfer through catalyst $\left(R_{m}\right)$ is excluded because of its negligibly small value. A discussion on the double-layer capacitance $\left(C_{d l}\right)$ will be dealt with in detail in a later section.

The changes in three kinds of resistances $\left(R_{\mathrm{ct}}, R_{e}\right.$, and $\left.R_{p}\right)$ in the DMFC anode during the conditioning process have been explicated from the impedance data. These three resistances for each MEA are shown in Fig. 6. In the case of MEA1 a significant decrease followed by a gradual stabilization is found for all the resistances dur- ing a period of the first $12 \mathrm{~h}$. In particular, $R_{p}$ decreases dramatically compared to other resistances, though its initial value is almost the same as the others. However, all three resistances in HT-treated MEA2 are larger than those in RT-treated MEA1, and the reduction in $R_{p}$ is not significant in spite of fast hydration and subsequent stabilization. The difference between the $R_{p}$ values of the RT-treated and HT-treated MEAs is larger $(20 \mathrm{~m} \Omega)$ than that in other resistances $\left(R_{\mathrm{ct}}\right.$ and $\left.R_{e}\right)$ (ca. $10 \mathrm{~m} \Omega$ ), probably because the recast ionomer in the catalyst layer is most significantly affected by temperature, as mentioned previously. The higher values of $R_{e}$ and $R_{\mathrm{ct}}$ for the HT-treated MEAs may arise from the contact resistance between the catalyst layer and electrolyte membrane, as well as another contact resistance between the catalyst particles and recast ionomer in the catalyst layer due to the loosened ionomer structure.

In the cases of MEA3 and MEA4 to which a constant load $\left(100 \mathrm{~mA} / \mathrm{cm}^{2}\right)$ was applied, the resistances measured during the first $2 \mathrm{~h}$ were smaller and they approached a steady value quicker than those in MEA1 and MEA2. A rapid reduction in the resistances and the resulting improved cell performances may be ascribed to the expectation that electric load might have accelerated the catalyst activation as well as the hydration of polymer electrolyte.

It is known that capacitance represents the extent of double-layer formation at the interface between the electrode (catalyst particles) and electrolyte (recast ionomer) and it increases with an increase in the area of the double layer. ${ }^{20,21}$ Therefore, the magnitude of capacitance reflects the effective area of the three-phase boundary available for electrochemical reactions. The double-layer capacitance $\left(C_{d l}\right)$ of each electrode was found to vary during the conditioning process, as shown in Fig. 7. The capacitances of the RT-treated MEAs increased rapidly and reached a maximum value during the first 12-h duration, but those of the HT-treated MEAs were much lower and rarely changed, as in the cases of various resistances (see Fig. 6). This implies that the interfacial area between the ionomer and catalyst particles could be significantly affected by the temperature that influences the structure of the recast ionomer in contact with a methanol solution.

The results of the present investigation offer an insight regarding the changes in the structural and electrochemical properties of the MEAs during various steps in the preconditioning processes. The transient behavior of the DMFC can be attributed mainly to the structural change of the recast ionomer that exists in the catalyst layer, as well as between the electrode and electrolyte membrane. A perfluorosulfonate ionomer, such as Nafion, is composed of hydrophobic fluorocarbons and hydrophilic ionic groups. ${ }^{22}$ When the ionomer is hydrated, the ionic groups form interconnected clusters that determine the electrochemical properties, whereas the fluorocar- 


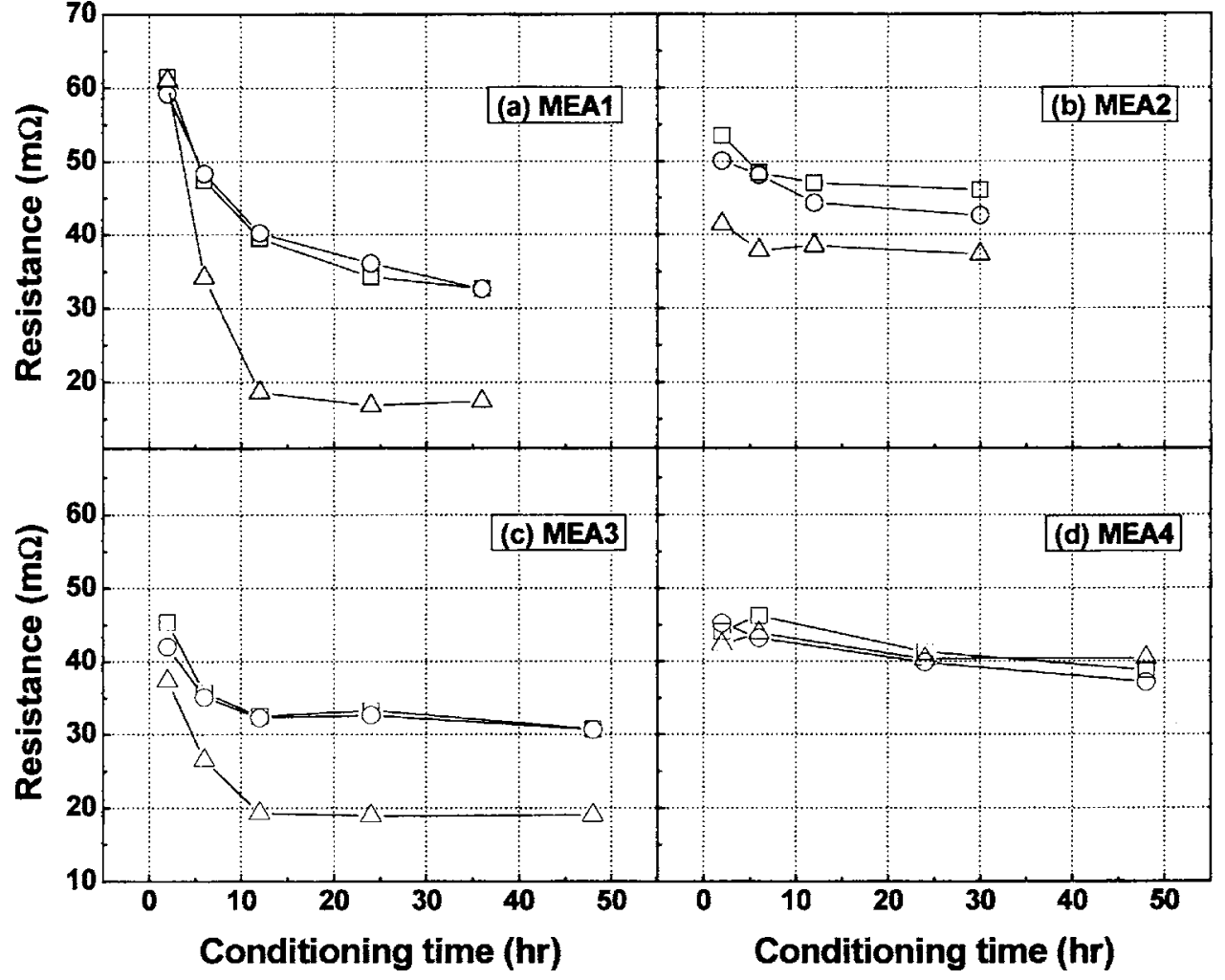

Figure 6. Changes in resistance elements calculated from the equivalent circuit of the MEAs during the preconditioning processes: $(\square)$ charge-transfer resistance $\left(R_{\mathrm{ct}}\right),(\bigcirc)$ : electrolyte resistance $\left(R_{e}\right)$, and $(\triangle)$ : pore electrolyte resistance $\left(R_{p}\right)$. bon phase influences the swelling level as well as the mechanical properties of the ionomer depending on the extent of its crystallinity. The structure and crystallinity of the recast ionomer film, which is made of ionomer solution, is dependent on the preparation condition, especially on the solvent of the ionomer solution. ${ }^{17,22} \mathrm{~A}$ recast ionomer with low crystallinity can be dissolved easily in water or organic solvents due to a collapsed structure. ${ }^{17}$ The recast ionomer prepared through a hot-pressing process $\left(140^{\circ} \mathrm{C}, 150 \mathrm{~s}, 70 \mathrm{MPa}\right)$ would have shorter durability in solvents such as water and alcohols. ${ }^{13,23}$ Consequently, the recast ionomer film becomes somewhat loosened or dissolved in alcohol or water compared to a commercial Nafion membrane, and its structural change is more prominent at high temperature. Therefore, the HT-treated MEAs exhibit

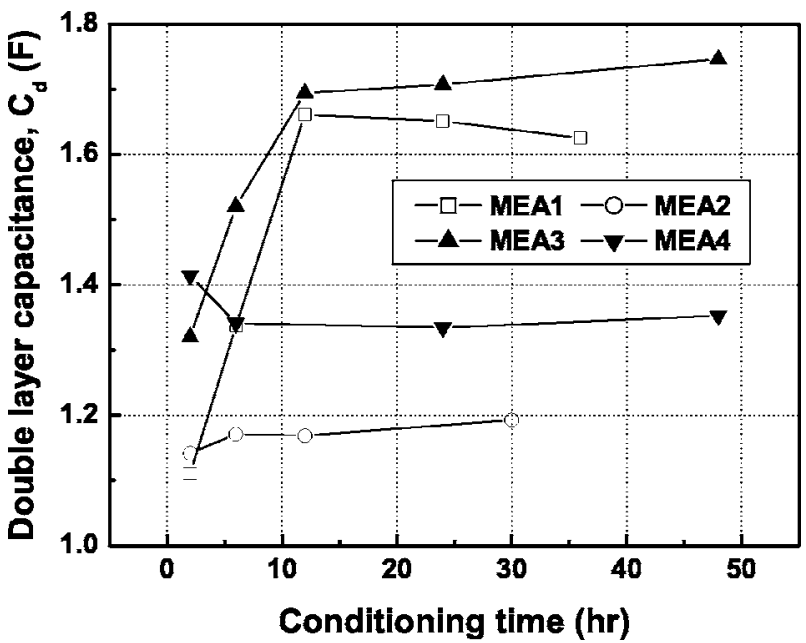

Figure 7. Changes in capacitance calculated from the equivalent circuit of MEAs during the preconditioning processes. increased ohmic resistances compared with the RT-treated MEAs, as evidenced by the higher impedance and the detachment of catalyst layer from the electrolyte membrane.

The application of an electric load during the preconditioning process appeared to induce the rapid hydration of polymer electrolytes and activation of the catalyst. When the electrochemical reactions proceed to produce protons under the application of an electric load, water transport from anode to cathode is accelerated by electro-osmotic drag. ${ }^{14}$ Thus, the ionic conductivity of the whole MEA increases rapidly due to the swift and substantial hydration of membrane and electrodes. In addition, the roughening of catalyst particles due to the proceeding electrochemical reaction helps to enhance the active surface area for methanol oxidation, ${ }^{15}$ leading to a decrease in charge-transfer resistance $R_{\mathrm{ct}}$ and an increase in performance.

\section{Conclusions}

The transient behaviors of DMFCs during preconditioning have been investigated focusing on the changes in the anode. The impedance data of the anodes were measured and subsequently deconvoluted using an equivalent circuit to extract various resistance elements associated with methanol oxidation processes in the anode.

The performance of DMFCs varied during the preconditioning process depending on the treatment method employed. It was found that the anode consisting of catalyst particles and polymer electrolyte underwent activation and swelling during the preconditioning process, which were affected by the conditions, such as temperature and electric load imposed. When a methanol solution was introduced into the anode compartment of the DMFC at room temperature, the polymer electrolyte both in the membrane and in the anode became suitably hydrated and swollen, leading to a decrease in the pore electrolyte resistance $R_{p}$ as well as the membrane resistance $R_{e}$. Furthermore, the charge-transfer resistance $R_{\mathrm{ct}}$ dropped to a lower value and the double-layer capacitance $C_{d}$ was raised, indicating the enlargement in the interfacial area between the catalyst and recast ionomer. However, at high temperature $\left(90^{\circ} \mathrm{C}\right)$, substantial improve- 
ment in $R_{\mathrm{ct}}, R_{p}$, and $C_{d}$ was not observed, presumably due to the collapsed ionomer network and the reduced three-phase region. The electric load imposed on the cell during the conditioning process appeared to accelerate the hydration of polymer electrolyte in the MEA and to increase the activity of catalyst.

Hence, an optimization of preconditioning method is essential to attain an improved performance in DMFCs, because the MEAs undergo structural and electrochemical changes during operation.

\section{Acknowledgments}

This work was financially supported by the Korean Ministry of Commerce, Industry and Energy, through the Institute of Industrial Technology Evaluation and Planning (ITEP) under the research program Development of Advanced Technologies for Next Generation, and by the Korea Science and Engineering Foundation through the Research Center for Energy Conversion and Storage. The authors also thank Dr. M. Aulice Scibioh for her help in preparing this article.

Korea Institute of Science and Technology assisted in meeting the publication costs of this article.

\section{References}

1. A. S. Aricò, P. Cretì, P. L. Antonucci, J. Cho, H. Kim, and V. Antonucci, Electrochim. Acta, 43, 3719 (1998).

2. A. K. Shukla, P. A. Christensen, A. J. Dickinson, and A. Hamnett, J. Power Sources, 76, 54 (1998).

3. K. Scott, W. M. Taama, P. Argyropoulos, and K. Sundmacher, J. Power Sources,
83, 204 (1999).

4. C. He, Z. Qi, M. Hollett, and A. Kaufman, Electrochem. Solid-State Lett., 5, A181 (2002)

5. J.-H. Kim, H. Y. Ha, I.-H. Oh, S.-A. Hong, and H.-I. Lee, J. Power Sources, 135 29 (2004)

6. P. Delahay, New Instrumental Methods in Electrochemistry, Chap. 7, WileyInterscience, New York (1954)

7. I. D. Raistrick, Electrochim. Acta, 35, 1579 (1990).

8. A. Lasia, J. Electroanal. Chem., 397, 27 (1995).

9. H. Göhr, Electrochemical Applications, 1/97, 2 (1997)

10. C. A. Schiller, F. Richter, E. Gülzow, and N. Wagner, Phys. Chem. Chem. Phys., 3, 2113 (2001)

11. A. Hamnett, Catal. Today, 38, 445 (1997).

12. I. Epelboin and M. Keddam, J. Electrochem. Soc., 117, 1052 (1970).

13. Z. Siroma, N. Fujiwara, T. Ioroi, S. Yamazaki, K. Yasuda, and Y. Miyazaki, $J$. Power Sources, 126, 41 (2004).

14. X. Ren and S. Gottesfeld, J. Electrochem. Soc., 148, A87 (2001).

15. H. Varela and K. Krischer, J. Phys. Chem. B, 106, 12258 (2002).

16. J. Nordlund, A. Roessler, and G. Lindbergh, J. Appl. Electrochem., 32, 259 (2002).

17. G. Gebel and B. Loppinet, in Ionomers: Characterization, Theory, and Applications, S. Schlick, Editor, p. 102, CRC Press, Boca Raton, FL (1996).

18. J.-H. Kim, H. Y. Ha, I.-H. Oh, S.-A. Hong, H.-N. Kim, and H.-I. Lee, Electrochim Acta, 50, 801 (2004)

19. T. E. Springer, T. A. Zawodzinski, M. S. Wilson, and S. Gottesfeld, J. Electrochem. Soc., 143, 587 (1996).

20. K. B. Oldham and J. C. Myland, in Fundamentals of Electrochemical Science, p. 17, Academic Press, Inc., San Diego, CA (1994).

21. Z. Siroma, T. Sasakura, K. Yasuda, M. Azuma, and Y. Miyazaki, J. Electroanal. Chem., 546, 73 (2003).

22. W. Grot, in Encyclopedia of Polymer Science and Engineering, H. F. Mark and J. I. Kroschwitz, Editors, Vol. 16, pp. 642-648, Wiley, New York (1989).

23. S.-Y. Ahn, Ph.D. Thesis, Sungkyunkwan University, Korea (2002). 